DOI https://doi.org/10.30525/978-9934-26-046-9-27

\title{
METHOD OF CALIBRATION OF ELECTRICAL MEASURING DEVICES OF ALTERNATING CURRENT BY SQUARE WAVE SIGNALS
}

\author{
Mosharenkov V. V. \\ Candidate of Technological Sciences, Senior Lecturer \\ Ivan Kozhedub Kharkiv National Air Force University \\ Velychko V. A. \\ Lecturer \\ Ivan Kozhedub Kharkiv National Air Force University \\ Koval O. V. \\ Candidate of Technological Sciences, Senior Lecturer \\ Ivan Kozhedub Kharkiv National Air Force University \\ Kharkiv, Ukraine
}

These days, the calibration of electrical measuring devices of alternative current (EMDAC) is carried out by sinusoidal calibration analog signals, and the technical and metrological requirements for calibrators of such signals are constantly increasing. Meeting these requirements is causing greater circuit difficulties and cost. Moreover, the reproduction of such signals with high accuracy in setting tunable parameters (amplitude, frequency, and phase) with a minimum harmonic coefficient is a very complicated task, and the complexity of its solution increases with increasing accuracy requirements for setting these parameters. For rectifying and electronic EMEAC, which are the most widely used in the ranges of sound and high frequencies, measuring converters (detectors) of mean-rectified and amplitude values into direct current or voltage are used, which are then measured by a magneto-electric device with a graduation of its scale in the mean-square values of the measured signal with the corresponding shape factors $\left(K_{s h}=1,11\right)$ and amplitudes $\left(K_{a}=\sqrt{2}=1,41\right)$ for a sinusoidal signal. Deviation of the real signal from the sinusoidal signal leads to a systemic methodological error, which can be calculated and taken into account only for a strictly specified signal form. In fact, it is unknown and it must be determined before with certain accuracy. Thus, with the development of digital measuring equipment, including digital signal generators 
(and calibrators) [1], a certain research interest is caused by the problem of calibrating EMIAC by square wave signals rather than sinusoidal signals.

View of the foregoing, the research of the possibility of calibrating EMDAC with square wave signals closer to the real measured signals than sinusoidal signal seems natural. There are known works in this research area [2-4], and this report is dedicated to the presentation of the results of further development of the theory of using square wave signals with adjustable time parameters.

Let us suppose that the EMDAC measuring circuit is affected by a periodic sequences of bipolar symmetrical square wave pulses with arbitrary and adjustable time parameters ( pulse duration and pause between them), i.e. with adjustable duty cycle . Such calibration signal (CS) is shown in Fig. 1, where: $\mathrm{T}$ is period , $U_{0}$ is amplitude, $\tau$ is duration (width) of the pulses.

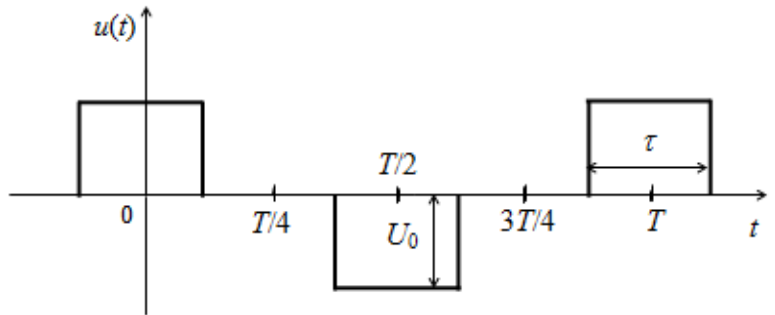

Fig. 1. Calibration signal in the form of a periodic sequence of bipolar square wave pulses with adjustable time parameters

The analytical expression for the signal $u(t)$ has the following form:

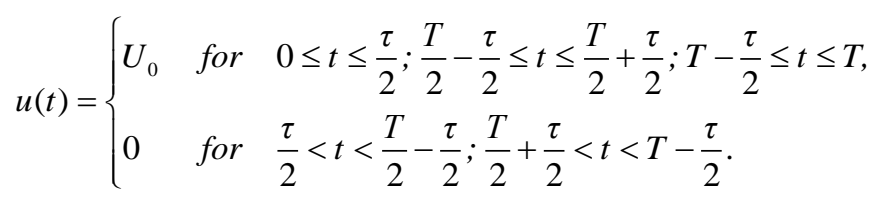

The calibrated device readings (ammeter or voltmeter) are determined by the root-mean square (RMS) of the current:

$$
I^{2}=\frac{1}{2} \sum_{n=0}^{\infty}\left|\dot{I}_{n m}\right|^{2},
$$


where $\dot{I}_{n m}$ - complex amplitude of $n$-th current harmonic in the measuring circuit of EMDAC.

The conversion will allow us to put this expression in the following form

$$
I^{2}=\frac{4 U_{0}^{2}}{\pi^{2} R^{2}} S
$$

where

$$
S=\sum_{k=-\infty}^{\infty} \frac{\sin ^{2}(2 k+1) \frac{\pi}{2} \eta}{(2 k+1)^{2}} R[j(2 k+1)]
$$

$\eta$ - volume efficiency or value, inverse duty cycle $Q=T /(2 \tau)$ signal $u(t)$, i.e $\eta=1 / Q=2 \tau / T$.

Omitting the intermediate calculations, let us conduct a research to obtain a mathematical model of the methodological error, as a result we will get:

$$
\Delta S=\pi \sum_{n} \frac{/ A_{n}}{q_{n}^{2}} H
$$

where

$$
H=\frac{\operatorname{ch} \frac{\pi(1-\eta)}{2} q_{n} \operatorname{sh} \frac{\pi \eta}{2} q_{n}}{\operatorname{ch} \frac{\pi}{2} q_{n}} .
$$

We will finally get such result after calculation

$$
I^{2}=\frac{U_{0}^{2} \eta}{R^{2}}=\frac{U_{0}^{2}}{R^{2} Q} .
$$

Expression (6) represents a mathematical model of calibrating electromechanical ammeters and voltmeters of a square wave CS with adjustable duty cycle $Q$ or its inverse value $\eta$.

Let us research the methodological error of such calibration. 
The condition $\operatorname{Re} \eta q_{n}>>1$ corresponds to the low reactivity in the measuring circuits of calibrated devices. Using the expansion of hyperbolic functions in power series to a linear term [5-9], we will have

$$
\operatorname{sh} \frac{\pi \eta}{2} q_{n} \approx \frac{1}{2} e^{\frac{\pi \eta}{2} q_{n}} ; \operatorname{ch} \frac{\pi}{2} q_{n} \approx \frac{1}{2} e^{\frac{\pi}{2} q_{n}} .
$$

After substituting the equalities (7) into formula (5), for the value $H$ we will obtain

$$
H=\frac{\operatorname{ch} \frac{\pi(1-\eta)}{2} q_{n} e^{\frac{\pi \eta}{2} q_{n}}}{e^{\frac{\pi}{2} q_{n}}}=\frac{1}{2}\left[1+e^{-\pi(1-\eta) q_{n}}\right],
$$

Let us consider two limiting cases for the value $H$ :

a) if $\operatorname{Re}(\overline{1-\eta}) q_{n}>>1$, from formula (8) we obtain $H=1 / 2$;

b) if $\operatorname{Re}(\overline{1-\eta}) q_{n}<<1, H=1$.

According to the ratio (4), the value $\Delta S$ is specified for each of the cases and takes the form accordingly

$$
\Delta S_{1} \approx \frac{\pi}{2} \sum_{n} A_{n} / q_{n}^{2} ; \Delta S_{2} \approx \pi \sum_{n} A_{n} / q_{n}^{2} .
$$

A similar value for $\Delta S_{0}$ for $\eta=1(\mathrm{CS}$ «meander» type) for the same functions is determined by the relation:

$$
\Delta S_{0} \approx \sum_{n} A_{n} / q_{n}^{2} .
$$

Comparing equality (10) with equality (11) we will have

$$
\Delta S=H \Delta S_{0},
$$

where

$$
H=\left\{\begin{array}{l}
1 \text { if } \operatorname{Re}(\overline{1-\eta}) q_{n}>>1 \\
\frac{1}{2} \text { if } \operatorname{Re}(\overline{1-\eta}) q_{n}<<1
\end{array}\right.
$$


Moving to the methodological error of calibration of the EMDAC taking into consideration the ratio (12) we will obtain the generalized expression.

$$
\delta I=\frac{H}{\eta} \delta I_{0}=H Q \delta I_{0}
$$

where $\delta I_{0}$ is the relative methodological error of calibration of EMDAC for CS «meander» type, depending on the type of measuring circuit of EMDAC.

Let us specify the relation (13), that allows to evaluate the relative value of methodological error of the task RMS of current in the measuring mechanism EMDAC, where the small inductance is not equilibrate with capacity, under its calibration by square wave signal "meander" type for measuring circuit of EMDAC:

a) without inductance compensation:

$$
\delta I_{1}^{\prime}=-\frac{H \varepsilon}{\pi \eta}=-\frac{H \omega_{0} L}{\pi \eta R}
$$

b) reactivity compensated:

$$
\delta I_{2}^{\prime}=\frac{H \omega_{0} L}{\pi \eta R} .
$$

When the relative methodological error of calibration $\delta I_{1}^{\prime}, \quad \delta I_{2}^{\prime}$ EMDAC is preset, formulae (14), (15) determine the allowed limits of variations of duty cycle of CS during sitting of the calibrated device readings

$$
Q<\left|\delta I^{\prime}\right| \frac{R}{\omega_{0} L} .
$$

A generalized mathematical model of the methodological error for a square wave CS with adjustable time parameters has been obtained. The generalized mathematical model of the error has been specified for both types of the measuring circuit of electromechanical ammeters and voltmeters: without compensation and with compensation of the inductance of the coil of the measuring mechanism. 
To sum up what have been said, the conducted analysis shows the possibility of using a periodic sequence of square wave pulse with adjustable duty cycle for the calibration of electrical ammeters and AC voltmeters. Setting a calibrated mark (RMS of CS) is set by changing the duty cycle (duration of square wave pulse) at a given nominal period (nominal frequency) of the signal. It will allow to reduce the methodological error of the calibrated mark when using square-wave signals.

\section{References:}

1. Dyakonov, V. P. (2009), Generation and signal generators, DMK Press, Moscow, 384 p.

2. Rybin, Yu. (2014), Measuring Signal Generators. Theory and Design, Springer; Dordrecht, Heidelberg, London, New York, 488 p.

3. Chinkov, V.M. and Herasymov, S.V. (2014), »Metodyka syntezu vymiriuvalnykh syhnaliv dlia kontroliu tekhnichnoho stanu zrazkiv ozbroiennia pry intehralnomu obmezheni» [Method of synthesis of measurings signals for control of the technical state of standards of armament at integral limitation], Systems of Arms and Military Equipment, No. 1(37), Pp. 84-87.

4. Mynts, M.Ya. and Chinkov, V.M. (1980), «Ob yspolzovanyy syhnalov priamouholnoi formy dlia poverky elektromekhanycheskykh pryborov» [On the use of rectangular signals for testing electromechanical devices], Measuring technique, No. 3. Pp. 42-43.

5. Mynts, M.Ya. and Chinkov, V.M. (1987), «Calibration of electromechanical devices with rectangular signals with adjustable duty cycle» [Poverka elektromekhanicheskikh priborov signalami priamougolnoi formy s reguliruemoi skvazhnostiu], Measuring technique, No. 4. Pp. 64-66.

6. Mosharenkov, V. (2020) «Development of methodological errors assessment method calibration electric measuring devices of current rectangular wave from the «meander» type», Control, Navigation and Communication Systems. Academic Journal. Poltava: PNTU, 3(61), Pp. 41-43. doi: https://doi.org/10.26906/SUNZ.2020.3.041.

7. Vygodskii, M. (2006), Handbook of higher mathematics, AST, Moscow, 991 p. - ISBN 5-17-0122338-1

8. Demidovich, B.P. and Kudriavtsev, V.A. (2001), Short course in higher mathematics, Astrel, Moscow, 655 p.

9. Dvait, G.B. and Semendiaev, K.A. (2005 ), Integral tables and other mathematical formulas, Lan Publishing, St. Petersburg, 232 c. ISBN 5-8114-0642-8. 